\title{
Healthcare resource utilization among haemophilia A patients in the United States
}

\author{
L. A. VAlENTINO, $*$ S. W. PIPE, $\uparrow$ M. D. TARANTINO, $\$$ X. YE, $\mathbb{Y}$ Y. XIONG and M. P. LUO $\mathbb{S}$ \\ *Departments of Pediatrics and Internal Medicine, Rush Hemoplilia and Thrombophilia Center, Rush University Medical Center, \\ Chicago, IL; $\dagger$ Department of Pediatrics and Pathology, University of Michigan, Ann Arbor, MI; $\ddagger$ Bleeding and Clotting Disorders \\ Institute, Peoria, IL; $\$$ Medical Outcomes Research and Economics, Baxter Bioscience, Deerfield, IL; and Medical Outcomes \\ Research and Economics, Baxter Bioscience, Westlake Village, CA, USA
}

\begin{abstract}
Summary. Advances in therapy have improved life expectancy and quality of life of patients with haemophilia A. Due to the chronic and complex management of this disease, particularly, the development of inhibitors, little is known about their health resource utilization in the real-life setting over time. The aim was to assess the distribution and trend of healthcare resource utilization among US haemophilia A patients with and without inhibitors. The MarketScan ${ }^{\circledR}$ Database, was queried to identify individuals with $\geq 1$ year continuous enrolment, two medical diagnoses of haemophilia A and claims for factor VIII or bypassing agent (to infer inhibitor status) during 2001-2007. Haemophilia-related cost was estimated from inpatient, outpatient and pharmacy claims. Annual cost differences were assessed by age and over a 4-year period for those with continuous enrolment. Among 51 million covered lives, 1044 haemophilia patients were identified, of whom 981 (94\%; mean
\end{abstract}

age $=21.2$ years $)$ did not have an inhibitor. The median haemophilia-related cost for these patients was $\$ 63,935$ per patient per year. When normalized by weight, annual cost was stable (no statistically significant differences) among 312 non-inhibitor patients (mean age $=21.8$ years) with 4 -year continuous data. While there was a wide distribution of haemophilia-related cost among the 63 individuals with an inhibitor (mean age $=15.4$ years), only $0.6 \%$ of the total haemophilia patients had costs exceeding $\$ 1$ million per patient per year. This study indicated that most haemophilia A patients were inhibitor-free with relatively stable annual costs over time. There was a wide distribution of haemophilia-related cost for inhibitor patients, while the proportion of patients who incurred extreme high cost was low.

Keywords: cost, economics, haemophilia, inhibitors, surgery

\section{Introduction}

Haemophilia A is a rare, genetic bleeding disorder resulting from the deficiency of factor VIII (FVIII) activity. Patients with this condition may have easy bruising and excessive bleeding. Complications from bleeding include pain, swelling, limited range of motion of joints and reduced quality of life (QoL). Bleeding that is uncontrolled or into a vital structure may result in death.

Treatment of haemophilia A involves replacing FVIII activity, typically by injection of either plasma-derived or recombinant FVIII. Due to the chronic and complex

Correspondence: Michelle P. Luo, PhD, Medical Outcomes Research \& Economics, Baxter BioScience, One Baxter Parkway, Deerfield, IL 60015, USA.

Tel.: +847940 5559; fax: +847940 5960;

e-mail: michelle_luo@baxter.com

Accepted after revision 23 September 2011 nature of the disease, clinical management of haemophilia A patients is heavily impacted by disease severity, weight, treatment regimen, complications and other factors [1-4]. The treatment pattern for haemophilia has evolved significantly over time, in particular, with paediatric patients. In the US in 1995, the prevailing practice was to utilize FVIII treatment in response to bleeding episodes (on-demand treatment) and only 33\% of children with haemophilia received regular administration of FVIII (prophylaxis) [5]. In the last decade, prophylaxis treatment has increased, especially in young patients [6-8]. This increase in prophylaxis use is attributable to recent evidence that it reduces bleeding episodes and joint disease $[9,10]$. This and advances in therapy agents have raised the life expectancy of haemophilia A patients to near normal [11] and significantly improved their QoL [12].

From a clinical perspective, haemophilia $\mathrm{A}$ has been transformed from a fatal disease to a well-managed, 
chronic disease for patients who have not developed complications. However, the onset of complications, particularly development of inhibitors, may add significant complexity to disease management [13]. Currently, prevalence of inhibitors among haemophilia A patients is $5-7 \%$ [14] and the cumulative incidence is $20-30 \%$ [14-16]. The presence of inhibitors greatly impacts the health and QoL of haemophilia A patients, due to the difficulty to control bleeding and joint disease $[17,18]$. Treatment of inhibitor patients may involve immune tolerance induction (ITI) to eradicate inhibitors and clotting agents, such as activated recombinant FVII (rFVIIa) or an activated prothrombin complex concentrate (aPCC) to bypass inhibitors in an attempt to control bleeding episodes [19]. Clinical management of haemophilia patients with inhibitor development is individualized to a large extent due to the many ITI protocols available and different patient responses to ITI, aPPC and rFVIIa [20-22].

Given improvement in life expectancy, the potential for complications and the complexity of individualized treatment of inhibitor patients, it is important to understand the health resource utilization among haemophilia A patients. This study assesses the trend and distribution of healthcare resource utilization and treatment costs of haemophilia A patients by looking at real-world data in a large US health insurance claims database. It also sheds light on the distribution of healthcare resource utilization associated with inhibitor management.

\section{Methods}

\section{Data source}

The MedStat MarketScan ${ }^{\circledR}$ Database, a large US healthcare claims database including data from employer-based commercial health plans, Medicare Supplemental and Medicaid sources was analysed. The dataset includes medical claims (i.e. inpatient/ outpatient), outpatient pharmacy claims and annual enrolment information from 2001 to 2007.

\section{Sample selection}

Inclusion criteria were male individuals with at least two diagnoses for haemophilia A (ICD-9-CM 286.0-congenital FVIII disorder) recorded at least 30 days apart. The first haemophilia A diagnosis identified in the database became the index date. Furthermore, they were required to have at least 1 year of continuous eligibility after the index date and at least one outpatient pharmaceutical claim for a FVIII product or bypassing agent. Individuals receiving at least one bypassing agent (i.e. aPCC or rFVIIa) were defined as inhibitor patients and the others as non-inhibitor patients.

\section{Statistical analysis}

The variables analysed were age at index date and haemophilia-related cost, including inpatient, outpatient and drug cost related to haemophilia treatment. Due to potential impact of growth-related weight gain on the rising annualized cost per patient in the paediatric population, annual haemophilia-related cost per patient was normalized by weight (per $\mathrm{kg}$ ). Patient weight was not available and therefore estimated using the proxy data from CDC growth charts [23]. Due to the skewed distribution of cost data, non-parametric statistics were used to assess cost differences between patient subgroups and over time. Mixed model regression was used to assess the effect of time on annualized cost per kg among a group of 312 patients who had 4-year continuous enrolment data. Dollars were adjusted to 2007 amount. Cost was adjusted to 2007 dollars using the Consumer Price Index - Medical Care Services Factor published by the United States Bureau of Labor Statistics [24].

\section{Results}

\section{Patient characteristics}

Figure 1 is a flow chart of sample selection. Among the 51 million covered lives assessed in the database, 1044 individuals (mean age $=20.9$ years) met the sample selection criteria for the study and were defined as haemophilia A patients. Of these patients, 94\% (981/ 1044) were identified as non-inhibitor patients during the eligible study period. Table 1 summarizes study population by age groups and inhibitor status. The ages of the non-inhibitor patients were relatively evenly distributed. It was expected that the number of patients

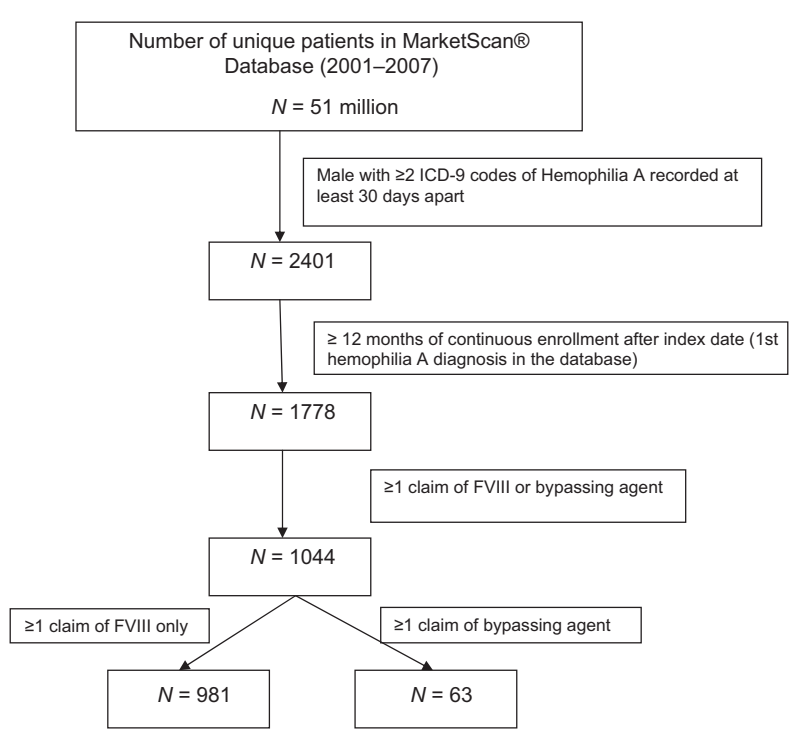

Fig. 1. Summary of the sample flow. 
Table 1. Patient age distribution by inhibitor status.

\begin{tabular}{lccc}
\hline $\begin{array}{l}\text { Age at } \\
\text { index } \\
\text { date }\end{array}$ & $\begin{array}{c}\text { Total number } \\
\text { by age } \\
\text { group }(\% *)\end{array}$ & $\begin{array}{c}\text { Number of } \\
\text { non-inhibitor patients } \\
\text { by age group }(\%)\end{array}$ & $\begin{array}{c}\text { Number of inhibitor } \\
\text { patients by age } \\
\text { group }(\%)\end{array}$ \\
\hline $0-5$ & $199(19)$ & $177(18)$ & $22(35)$ \\
$6-10$ & $179(17)$ & $167(17)$ & $12(19)$ \\
$11-15$ & $163(16)$ & $153(16)$ & $10(16)$ \\
$16-20$ & $130(12)$ & $126(13)$ & $4(6)$ \\
$\geq 21$ & $373(36)$ & $358(36)$ & $15(24)$ \\
Total & $1044(100)$ & $981(100)$ & $63(100)$ \\
Mean & $20.9 \pm 18.3$ & $21.2 \pm 18.3$ & $15.4 \pm 16.7$ \\
Median & $15(0-88)$ & $15(0-88)$ & $9(0-44)$ \\
\hline
\end{tabular}

"Percentage is calculated as the number of patients in the age group divided by the total number of patients in the category.

in the $\geq 21$ age group would be larger due to the wide age range in this group. Also as expected, the highest percentage $(35 \%)$ of inhibitor patients was in the $0-$ 5 year age group. The overall prevalence of inhibitors in the study population was 6\% (63 of 1044).

\section{Cost of non-inhibitor patients}

Haemophilia-related expenses were first examined for patients who did not have an inhibitor as defined above. Median annual haemophilia-related cost was \$63935 (Fig. 2). The majority of the cost came from haemophilia drug spending (median $=\$ 47626)$. The medians of the inpatient and outpatient cost were 0 and $\$ 867$, respectively. When stratified by age groups, the median annual haemophilia-related cost increased significantly $(P<0.05)$ for patients from birth to about 15 years, remained stable thereafter until 20 years and dropped significantly after patients reached 21 years of age $(P<0.05)$. When normalized by weight (Fig. 3), there was no statistically significant difference in annualized cost per $\mathrm{kg}$ among patient age groups $\leq 20$ years. However, those $\geq 21$ years of age had a median annual cost per $\mathrm{kg}$ of $\$ 595$ which was significantly lower compared with any age group less than 21 years $(P<0.001)$.

To determine the cost trend for managing noninhibitor haemophilia patients over time, longitudinal data were analysed for a cohort of 312 non-inhibitor patients (mean age $=21.8$ years, median age $=14$ years), who had over 4-year continuous enrolment in the database. As more than half of the 312 patients were paediatric patients under the age of 18 , the annual cost was normalized by weight to control the possible weight gain during the 4 -year period. Figure 4 presents the median annualized cost per $\mathrm{kg}$ over the 4-year interval for these patients. There was no significant difference in year-to-year change over the 4 years based on Wilcoxon signed rank test. Mixed regression analysis treating time as fixed effects was employed to further examine the effect of time on cost. The effect of time was not significant, confirming the stability of cost per kg over time.

\section{Cost of inbibitor patients}

A small percentage of haemophilia A patients $(6 \%)$ utilized a bypassing agent in this study. The medians for the inpatient, outpatient and drug costs were $\$ 7004$, $\$ 3430$ and $\$ 191301$, respectively. There was a wide distribution of annual haemophilia-related cost in these patients, ranging from $\$ 16013$ for patients in the 10th percentile to \$1 031314 for those in the 90th percentile, with a median cost of $\$ 271357$ (Fig. 5). Impor-

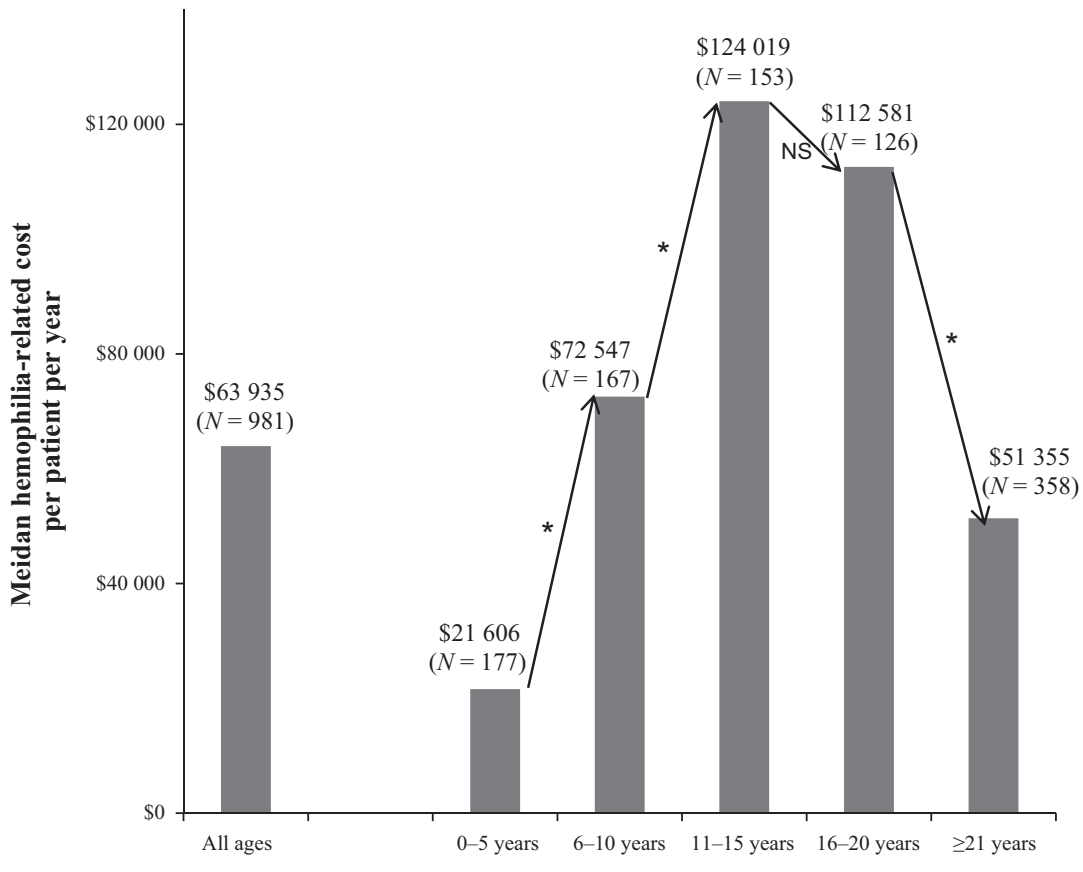

Fig. 2. Median annual haemophilia-related cost by age group for non-inhibitor patients $(N=981) .{ }^{*} P<0.05$ for cost comparison between adjacent groups ( $P$ values were computed using the Wilcoxon rank sum test). NS: not significant. 
Fig. 3. Median annual haemophilia-related cost per kg by age group for non-inhibitor patients $(N=981) . * P<0.001(P$ values were computed using the Wilcoxon rank sum test). The significant difference of annual cost per $\mathrm{kg}$ for the $\geq 21$ age group was in comparison with all other age groups. There was no significant difference in annual cost per $\mathrm{kg}$ when comparing every other two groups.
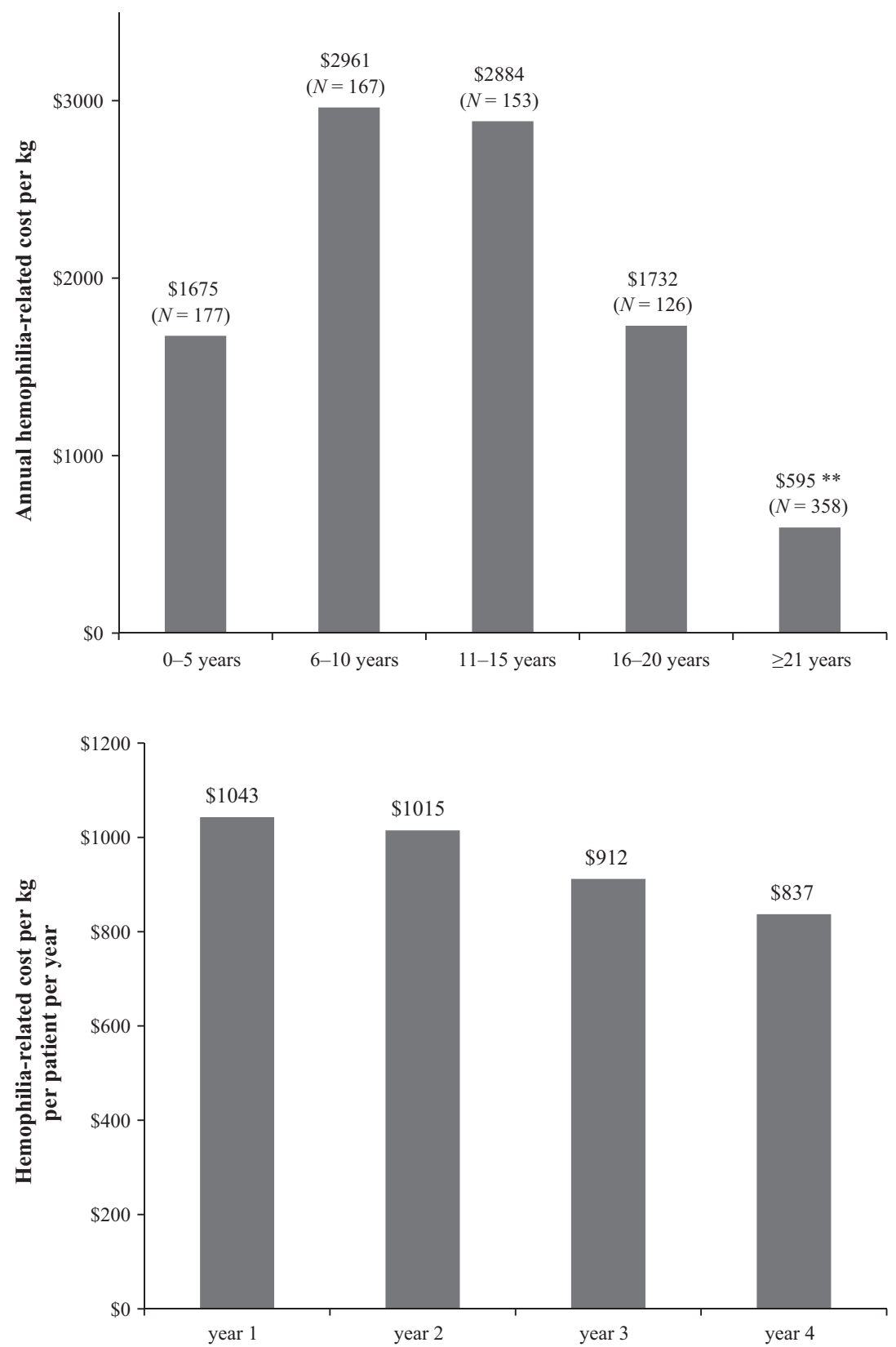

Fig. 4. Median haemophilia-related cost per $\mathrm{kg}$ over 4 years for non-inhibitor patients $(N=312)$. No differences were statistically significant. tantly, the proportion of inhibitor patients who had an annual cost exceeding \$1 million accounted for only $0.6 \%$ of the total haemophilia A study population (6 of 1044 patients).

Closer examination of the subset of patients with inhibitors by age group and by weight revealed that the highest cost $/ \mathrm{kg}$ was found among the $0-5$ years age group (Fig. 6). The youngest population had a statistically significant higher annual cost $/ \mathrm{kg}$ over the $6-10$ and $\geq 21$ age groups $(P<0.05)$. The small sample size in the 11-15 and 16-20 age groups may account for the lack of statistically significant difference compared to the 0-5 population. When comparing all age groups older than 5 years, cost per $\mathrm{kg}$ was not significantly different.
To determine other possible contributing factors towards the cost of haemophilia A patients with inhibitor development, surgery status and type of bypassing agents were analysed. The years in which inhibitor patients underwent at least one surgical procedure resulted in significantly higher cost $($ median $=\$ 286609)$ compared with years without surgery (median = $\$ 68$ 379) $(P<0.05)$ (Fig. 7). In a comparison of cost for inhibitor patients treated with either aPCC or rFVIIa (not both), the median annual haemophilia-related cost was $\$ 160019$ for patients utilizing aPCC $(n=16)$ and $\$ 258824(n=29)$ for patients treated with rFVIIa. However, no statistically significant difference was detected, possibly due to the small sample sizes. 

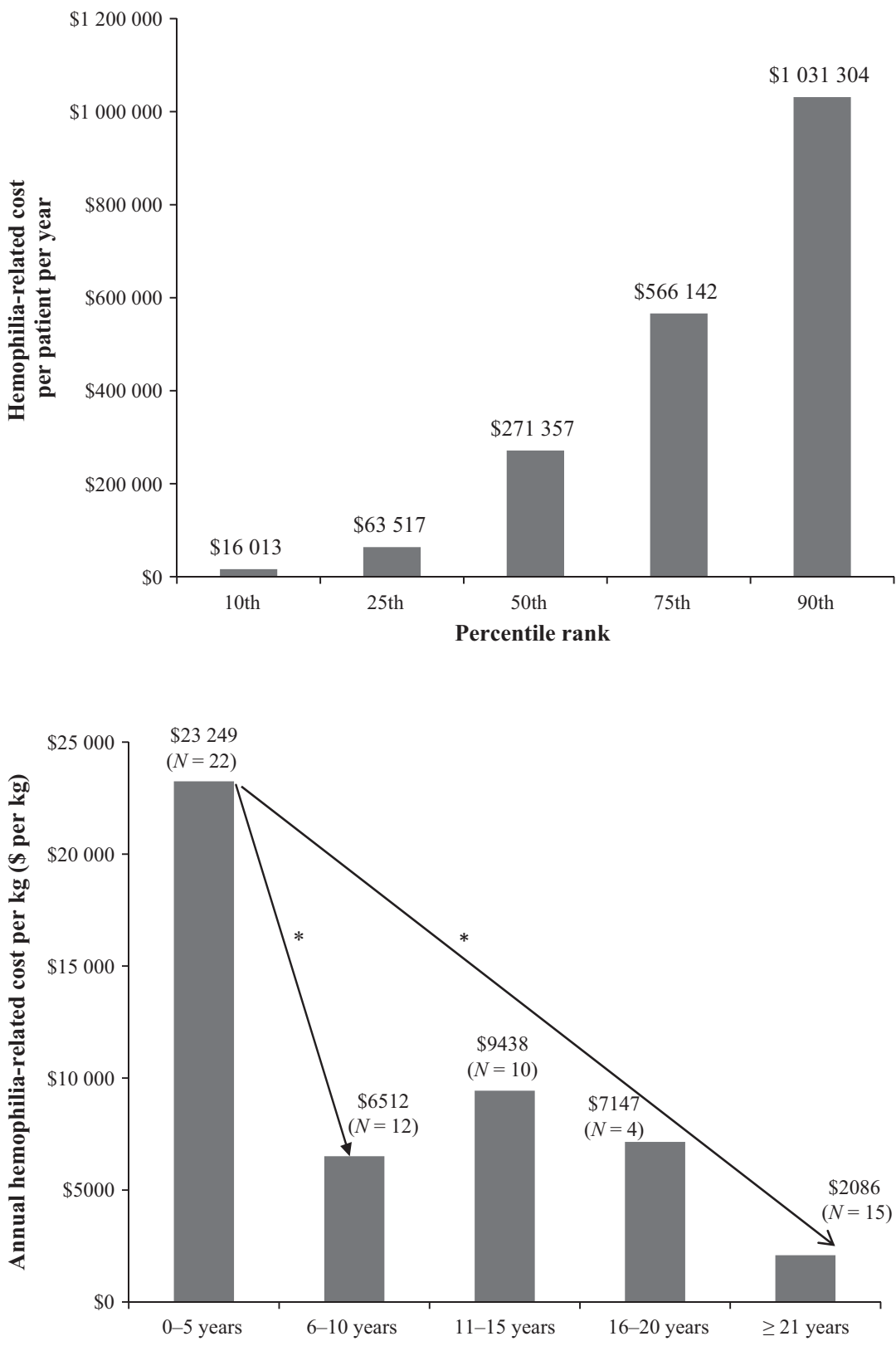

Fig. 5. Distribution of annual haemophiliarelated cost among inhibitor patients $(N=63)$. The proportion of inhibitor patients, who had a cost exceeding \$1 million per patient per year, accounted for only $0.6 \%$ of the total haemophilia A patients.

\section{Discussion}

Utilizing a large US healthcare database, this study showed that the great majority (94\%) of haemophilia A study patients did not develop inhibitors during the observation period and their total haemophilia-related treatment cost per patient per year was similar to what has been reported by other studies [1,2]. It also confirmed the known prevalence rate $(6 \%)$ of inhibitors, within the range of what has been reported in the literature [14,25].

This study further assessed the impact of age and weight on cost of haemophilia treatment. When normalized by weight, there was no statistical difference in total haemophilia-related cost among non-adult age groups ( $\leq 20$ years of age). However, there was a significant decrease in cost for the $\geq 21$ adult group vs. other age groups. The weight normalized cost differences between adults and children was consistent with the treatment pattern that a greater percentage of young patients are on a continuous prophylaxis regimen compared to adults [5,9]. Even when prophylaxis is prescribed, older patients were reported less likely to be adherent than younger patients [26].

In managing chronic diseases, it is always important to understand the total cost pattern over time. This is the first study that retrospectively followed a cohort of non-inhibitor haemophilia patients to analyse haemophilia-related costs over a 4-year time period. This 
Fig. 7. Median haemophilia-related cost for inhibitor patients by surgery status. ${ }^{*} P<0.05(P$ values were computed using the Wilcoxon rank sum test). Analysis of annual cost between surgery and non-surgery patients is based on person-year data. Each year of data per patient was categorized as either a surgery or non-surgery year. $N=51$ years (30 patients) for non-surgery; $N=136$ years ( 57 patients) for surgery.

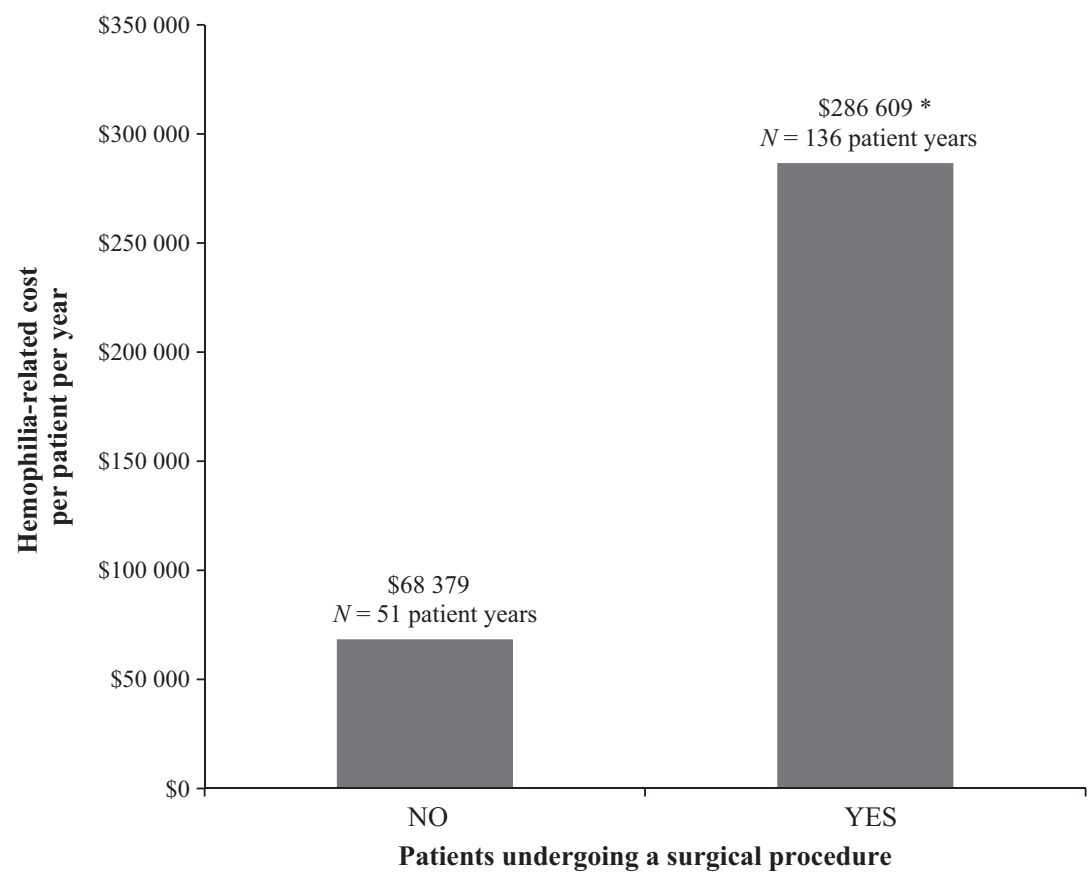

approach allowed assessment of the cost trend over time in the real-world setting. Although the median weight normalized cost (cost per $\mathrm{kg}$ ) showed a slight declining trend, there was no statistically significant year-to-year variation over the 4-year period. This result was further confirmed by regression model showing that time did not have a significant effect on haemophilia-related cost per $\mathrm{kg}$. These findings suggested that haemophilia patients were well-maintained and in relatively consistent clinical condition during the study period, which resulted in stability of total treatment costs over time.

A small proportion $(0.6 \%)$ of patients had high cost of care $(>\$ 1 \mathrm{M})$ due to inhibitor status. Interestingly, other analyses have shown that mean cost of inhibitor patients is inflated by a small number of patients with extreme outlier costs and after adjusting for these outliers, the cost of outpatient clotting factor replacement products was not significantly greater among inhibitor patients compared to non-inhibitor patients [27-29]. The management of patients with inhibitors to FVIII is complicated by less predictable responses to therapy with bypassing agents compared to replacement therapy in patients without inhibitors [21,22], which likely involves patient-specific factors and factors related to therapy agents, including the mechanisms of action and pharmacokinetic profiles. Therefore, inhibitor management is complex, making the widespread variation in costs understandable as care must be individualized not only for each patient, but also for specific haemorrhagic situations [4,30-32]. Co-determinants of cost in this study included age, weight, surgery and possibly which bypassing agent an inhibitor patient used. This study showed that patients $\leq 5$ years cost significantly more per $\mathrm{kg}$ than any other age group, possibly indicating that treatment of inhibitors for some of these patients involved ITI to eradicate inhibitors in combination with bypassing clotting agents. It may also reflect the lack of and/or differential responsiveness inherent in managing this rare population of haemophilia patients. The wide variation in overall haemophilia-related cost among patients with inhibitors demonstrates that optimized and individualized care is necessary among this small patient population.

The limitations of this study include the absence of patient-specific data, including haemophilia severity. However, patients with mild disease who did not use a FVIII product to treat bleeding would not be included in the analysis. Furthermore, there was no diagnosis code available for the identification of inhibitor patients and therefore this patient subgroup was operationally defined by utilization of bypassing agents. Presumably, there could have been inhibitor patients that were not identified, including those receiving FVIII for ITI and not having breakthrough bleeding requiring administration of a bypassing agent. In addition, prophylaxis use could be a confounding factor for cost. Such information was not available in the data. Therefore, the impact on cost from prophylactic treatment remained unknown. Finally, the actual weight of patients was not available and therefore the CDC average weight chart was used for any normalization to weight.

\section{Conclusion}

This study demonstrates that most haemophilia A patients were inhibitor-free (94\%) and haemophilia- 
related cost for most non-inhibitor patients was relatively stable over time with no significant year-to-year variation detected. In contrast, there was a wide distribution of haemophilia-related cost for inhibitor patients, while the proportion of patients who incurred extremely high costs was relatively low $(0.6 \%)$. This study provides a real-world snapshot of haemophiliarelated cost and advances the understanding of treatment patterns and the cost for treatment of haemophilia A patients with and without inhibitors to FVIII.

\section{Acknowledgements}

This study was sponsored by Baxter Healthcare. All authors contributed to research study design. The authors also thank Jocelyn Hybiske, PhD, for medical writing support.

\section{Author Contribution}

YX, XY and MPL analysed the data. XY and MPL provided statistical interpretation of the results, while LAV, SWP and MDT provided clinical interpretation of the results. All authors reviewed and contributed to manuscript writing.

\section{Disclosures}

LAV and Rush University Medical Center received grant support from Baxter, Bayer Healthcare, GTC Biotherapeutics, NovoNordisk, Pfizer, CSL Behring, Inspiration Bioscience and Biogen. LAV has acted as a paid consultant to Baxter, Bayer Healthcare, GTC Biotherapeutics, NovoNordisk, Inspiration Bioscience and Biogen. SWP has acted as a paid consultant to Baxter. MDT acted as a paid consultant to Baxter and has received funding for research on an unrelated effort. XY, YX and MPL are employees of Baxter and hold stock in Baxter.

\section{References}

1 Globe DR, Cunningham WE, Andersen R et al. The Hemophilia Utilization Group Study (HUGS): determinants of costs of care in persons with haemophilia A. Haemophilia 2003; 9: 325-31.

2 Globe DR, Curtis RG, Koerper MA. Utilization of care in haemophilia: a resourcebased method for cost analysis from the Haemophilia Utilization Group Study (HUGS). Haemophilia 2004; 10(Suppl 1): 63-70.

3 Fischer K, Van den Berg HM, Thomas R et al. Dose and outcome of care in haemophilia - how do we define cost-effectiveness? Haemophilia 2004; 10(Suppl 4): 216-20.

4 Colowick AB, Bohn RL, Avorn J, Ewenstein BM. Immune tolerance induction in hemophilia patients with inhibitors: costly can be cheaper. Blood 2000; 96: 1698-702.

5 Blanchette VS, McCready M, Achonu C, Abdolell M, Rivard G, Manco-Johnson MJ A survey of factor prophylaxis in boys with haemophilia followed in North American haemophilia treatment centres. Haemophilia 2003; 9(Suppl 1): 19-26.

6 Srivastava A, Giangrande PL, Poon MC, Chua M, McGraw A, Wiedel J. Guidelines for the management of hemophilia. Montreal, QC: World Federation of Hemophilia, 2005 .

7 Berntorp E, Boulyjenkov V, Brettler D et al. Modern treatment of haemophilia. Bull World Health Organ 1995; 73: 691-701.

8 Medical and Scientific Advisory Council. MASAC document 179. Recommendation Concerning Prophylaxis (Regular administration of clotting factor concentrate to prevent bleeding). 2007. Available at http:// www.hemophilia.org/NHFWeb/MainPgs/ MainNHF.aspx ? menuid $=57 \&$ contentid= 1007. Accessed July 28, 2011.

9 Geraghty S, Dunkley T, Harrington C, Lindvall K, Maahs J, Sek J. Practice patterns in haemophilia A therapy - global progress towards optimal care. Haemophilia 2006; 12: 75-81.

10 Manco-Johnson M, Abshire TC, Shapiro AD et al. Prophylaxis versus episodic treatment to prevent joint disease in boys with severe hemophilia. N Engl J Med 2007; 357: 53544

11 Mejia-Carvajal C, Czapek EE, Valentino LA. Life expectancy in hemophilia outcome. J Thromb Haemost 2006; 4: 507-9.

12 Aledort LM, Haschmeyer RH, Pettersson H. A longitudinal study of orthopaedic outcomes for severe factor-VIII-deficient haemophiliacs. The Orthopaedic Outcome Study Group. I Intern Med 1994; 236: 391-9.

13 Peerlinck K, Hermans C. Epidemiology of inhibitor formation with recombinant factor VIII replacement therapy. Haemophilia 2006; 12: 579-90.

14 Wight J, Paisley S. The epidemiology of inhibitors in haemophilia A: a systematic review. Haemophilia 2003; 9: 418-35.

15 Key NS. Inhibitors in congenital coagulation disorders. Br I Haematol 2004; 127: 379-91.

16 Aledort LM. Is the incidence and prevalence of inhibitors greater with recombinant products? Yes. J Thromb Haemost 2004; 2: 861-2.

17 Morfini M, Haya S, Tagariello G et al. European study on orthopaedic status of haemophilia patients with inhibitors. Haemophilia 2007; 13: 606-12.

18 Morfini M. Articular status of haemophilia patients with inhibitors. Haemophilia 2008; 14(Suppl 6): 20-2.

19 Dimichele DM. Management of factor VIII inhibitors. Int J Hematol 2006; 83: 119-25.

20 Mariani G, Kroner B. International immune tolerance registry, 1997 update. Vox Sang 1999; 77(Suppl 1): 25-7.

21 Leissinger CA. Prevention of bleeds in hemophilia patients with inhibitors: emerging data and clinical direction. $A m J$ Hematol 2004; 77: 187-93.

22 Ho AY, Height SE, Smith MP. Immune tolerance therapy for haemophilia. Drugs 2000; 60: 547-54.
23 Clinical Growth Charts. Centers for Disease Control and Prevention. 2000. Available at http://www.cdc.gov/growthcharts/clinical_ charts.htm. Accessed December 22, 2010.

24 Bureau of Labor Statistics. Consumer Price Indexes. Available at http://www.bls.gov/ data. Accessed June, 2011.

25 Ehrenforth S, Kreuz W, Scharrer I et al. Incidence of development of factor VIII and factor IX inhibitors in haemophiliacs. Lancet 1992; 339: 594-8.

26 Duncan N, Kronenberger W, Roberson C, Shapiro A. VERITAS-Pro: a new measure of adherence to prophylactic regimens in haemophilia. Haemophilia 2010; 16: 24755.

27 Chang H, Sher GD, Blanchette VS, Teitel JM. The impact of inhibitors on the cost of clotting factor replacement therapy in haemophilia A in Canada. Haemophilia 1999; 5: 247-52.

28 Ullman M, Hoots WK. Assessing the costs for clinical care of patients with highresponding factor VIII and IX inhibitors. Haemophilia 2006; 12(Suppl 6): 74-80.

29 Gautier P, D'Alche-Gautier MJ, Coatmelec $\mathrm{B}$ et al. Cost related to replacement therapy during hospitalization in haemophiliacs with or without inhibitors: experience of six French haemophilia centres. Haemophilia 2002; 8: 674-9.

30 Coppola A, Di Minno MN, Santagostino E. Optimizing management of immune tolerance induction in patients with severe haemophilia A and inhibitors: towards evidence-based approaches. Br J Haematol 2010; 150: 515-28.

31 Astermark J, Morado M, Rocino A et al. Current European practice in immune tolerance induction therapy in patients with haemophilia and inhibitors. Haemophilia 2006; 12: 363-71.

32 Di Paola J, Aledort L, Britton $\mathrm{H}$ et al. Application of current knowledge to the management of bleeding events during immune tolerance induction. Haemophilia 2006; 12: 591-7. 